\title{
O ESPAÇO GEOGRÁFICO: DA PERSPECTIVA GEOMÉTRICA À PERSPECTIVA EXISTENCIAL
}

\author{
Maria Laura Silveira*
}

\section{RESUMO:}

Historicamente, a geografia tem se preocupado com a extensão e sua operacionalização - a distância. Os esforços de compreensão orientaram-se, sobretudo, aos resultados - extensão, forma, tamanho, limites - e o espaço foi visto como inerte, como o final de um processo cuja indagação não nos pertence. Todavia, hoje, a existência, muito mais que a distância, parece ser o verdadeiro problema do homem e, especialmente, dos mais pobres. Uma geografia preocupada com a existência é, ao mesmo tempo, uma indagação sobre os eventos, as possibilidades e a ação humana que se tornou capaz de criar uma extensão planetária, mesmo que isto pretenda mascarar as demais formas de existência. É a ação humana que transforma as possibilidades em extensões. Por isso o centro de uma geografia da existência é o espaço banal, onde cada ação se dá segundo seu tempo, mas todas elas têm lugar.

\section{PALAVRAS-CHAVE:}

extensão, distância, existência, situação, espaço banal

\section{ABSTRACT:}

Historically, the geography has interested with extension and its operationalization - distance. Efforts of comprehension focused, particularly, the results - extension, form, size, boundary - and the space has seen as inert, as the end of a process without questions. Nevertheless, today, the existence, more than distance, it seems the principal problem of man and specially of poor people. A geography preoccuped about the existence is, at the same time, an indagation about events, possibilities and human action that can produced a planetary extension, although masking another forms of existence. The human action makes the possibilities in extensions. Consequently the essence of existencial geography is the common space, where every action has its time, but all of these exist.

\section{KEY WORDS:}

extension, distance, existence, situation, common space

\section{Introdução}

Dentre outras, duas grandes preocupações podem orientar a nossa discussão sobre o espaço geográfico. A primeira é a de revelar a natureza ou constituição do espaço, e a segunda é a de ver as formas de relação dentro dos níveis desse espaço, aquilo que tradicionalmente chama-se escala. $E$, de alguma maneira, isto coloca o problema de como podemos cindir o espaço na hora de enfrentar uma pesquisa, pois sabemos que esse tem sido um problema tradicional da geografia. Ambas preocupações fazem parte de um mesmo problema epistemológico.

Por isso, estamos chamando, de forma um pouco pretensiosa, epistemologia da extensão, a um conjunto de esforços históricos feitos na geografia para caracterizar tanto a constituição do espaço como, e sobretudo, a sua 
cisão. Por outro lado, buscaremos discutir, inspirados na teoria de Milton Santos, uma epistemologia da existência que possa ser a base de uma geografia mais preocupada com a produção de um concreto pensado cuja cisão seja parte do processo de compreensão da história.

\section{Epistemologia da extensão. Perspectivas geométricas ontem e hoje}

Nos albores da história, a organização do espaço mudava lentamente, prisioneira do peso dos fatores naturais que marcavam a produção da escala da vida. Os limites eram fixos e a vida, circunscrita aos lugares. Portanto, a distância e como superá-la era um problema existencial da humanidade. Ela podia, de alguma forma, ser a diferença entre a vida e a morte. Estava no cerne da idéia de sobrevivência e, com ela, a idéia de limite. As fronteiras foram primeiro ligadas ao mundo da natureza - a impossibilidade de ultrapassar uma cadeia de montanhas, um rio ou um mar -, mas depois e vagarosamente, tornaram-se uma construção política. Distâncias, limites, fronteiras eram problemas cotidianos que, com a passagem dos séculos e a persistente busca de conceitos que revelassem as formas fixas, inspiraram um vocabulário forte do saber geográfico.

Mas, a introdução de fatores de complexidade e a produção de dinamismos, ao longo da história, que alcança o paroxismo no período atual, em virtude dos acréscimos de ciência, tecnologia e informação, fizeram com que a vida ultrapassasse, a cada dia, esses limites, que pudesse ir além desses compartimentos determinados pela natureza no início da história, mais tarde desenhados pela cultura circunscrita de um povo e, hoje, desfeitos pelas permanentes acelerações que transformam a vida e o tamanho das regiões. Por exemplo, os limites de uma região metropolitana ou de uma área de cultura moderna são hoje permanentemente transformados na medida em que os fenômenos ganham novos conteúdos. Numa região como a Amazônia, os fatores ligados à natureza ainda têm um peso importante e, além das considerações da Amazônia legal, poderíamos dizer que os limites dessa região não se desmancham com tamanha velocidade, que são ainda estáveis e que a distância continua a ser um problema da existência.

Contudo, regiões onde os fatores da natureza comportam ainda esse peso são, hoje, pouco freqüentes. Em geral, no período contemporâneo, as idéias de distância, limite, fronteira são postas em questão. Num mundo assim construído e, ainda, com a força da ação de alguns agentes e de suas respectivas formas de discurso, muitas dessas distâncias foram superadas, levando a uma reformulação de limites, a uma necessária resignificação dos conceitos da nossa disciplina e a um conjunto de novos conceitos, dentre os quais, parecenos, o conceito de rede desponta com muita força no nosso vocabulário.

Nessa sucessão de contextos, ontem e hoje muitas geografias permanecem atreladas a uma visão do espaço como continente, uma concepção geométrica, feita de velhos e novos conceitos que privilegiam a distância. O centro da reflexão epistemológica parece ser a extensão, um conceito-chave ou, mesmo, uma categoria, que leva a uma resignificação do vocabulário tradicional. A preocupação epistemológica é a extensão e a forma de sua operacionalização, a distância, autorizando a falar de distância-tempo e de distância-custo na geografia, amparados também nas reflexões das ciências econômicas.

Podemos encontrar esforços bastante sisudos e bem-sucedidos no sentido de olhar criticamente a idéia de extensão, na história da disciplina, para que a distância não seja apenas uma distância física, mas uma distância medida em custos e em percepções. Um geógrafo como Antoine Bailly (1991) assevera que, diante das transformações do mundo atual, é preciso formular um novo paradigma epistemológico, resignificando os conceitos centrais da geografia, como a noção de distância. E esse 
mesmo autor, fazendo uma crítica, dirá que a concepção geométrica não é mais suficiente quando falamos de distância. Agora, é preciso diferenciar uma distância estándar, uma distância estrutural e uma distância afetiva. A primeira é aquela conhecida pelo homem primitivo, isto é, a distância física, relativa a um espaço geométrico que podemos mensurar em metros, quilômetros, etc. A distância estrutural é relativa aos sistema de relações e redes. Se uma cidadezinha, longe de um grande centro, foi alcançada por uma rede de telecomunicações e de transportes, podemos dizer que a distância "diminui". Por fim, a distância afetiva, que já foi valorizada pela geografia da percepção, chama a atenção sobre a relação sensível que cada um de nós tem com o espaço.

Philippe e Geneviève Pinchemel, no seu livro La Face de la Terre (1988), citam a definição de Wreford Watson para quem a geografia é uma disciplina em distância. Todo o arcabouço epistemológico, o núcleo duro da disciplina, poderia ser, em definitivo, relacionado a esse conceito central que é a distância. Para Pinchemel, esta é o primeiro fator da relação dos homens na superfície da Terra porque é o princípio de suas relações com tudo o que existe. Não há relação humana que não seja mediada pela distância que, inclusive, permite criar outros conceitos centrais, como periferia. Todavia, as distâncias que são hoje a base da organização do espaço não são mais as distâncias euclidianas, mas as distâncias humanas, aquelas relativas ao tempo, à atividade do homem.

Por outra parte, Roger Brunet inicia seu livro Le déchiffrement du monde (2001) definindo o que ele considera os conceitos basilares da geografia. A extensão é o primeiro escolhido e a noção oferecida é a do dicionário Lalande: uma linha, uma superfície, um volume limitado. Num esforço por geografizar essa definição geral, o autor dirá que tudo se descreve pelo sítio, pela forma e pelo tamanho. À idéia tradicional de sítio, fundada nas coordenadas e nas características físicas do lugar, ele acrescenta a forma e o tamanho como conceitos subsidiários da definição de extensão. E o autor vai mais longe quando afirma que uma das características do espaço é ter sempre uma medida, uma métrica, mesmo que a extensão seja descontínua e fragmentada. Exemplifica dizendo que uma empresa pode ter uma extensão fragmentada no mundo, mas isso não nos libera do esforço de produzir uma métrica, uma medida para a extensão que é um dos conceitos essenciais para definir a categoria maior que é o espaço. Pouco depois, Brunet afirma que o lugar é um ponto no globo, com atributos que podemos descrever. Cada lugar é identificável e único. Seu conteúdo é um assunto de escala, de análise, de percepção e de interpretação. A uma certa escala Paris é um ponto, um lugar, porém a outra escala Montmartre é um ponto e um lugar. Eis aí a antiga e renovada idéia da escala como zoom (Silveira, 1999a; 2004). O terceiro conceito é o que denomina espaço geográfico particular, isto é, uma porção da superfície terrestre definida por uma extensão e pelos atributos localizados no seu seio. É uma configuração definida a uma dada escala, por um conjunto de lugares sobre uma extensão determinada, dotada de atributos, identificável pelos seus contornos, mesmo quando descontínuos ou frouxos. Sem abandonar a tradição francesa, ele busca afirmar sua contribuição: o espaço geográfico particular ao qual nos referimos aqui não é nem o espaço homogêneo, abstrato, contínuo, infinito das teorias econômicas - agregariamos, tantas vezes, da corologia - nem é o espaço físico dito natural. O espaço geográfico particular é habitado, percorrido, humanizado.

Desse modo, para Brunet (2001), o lugar é um ponto e o espaço é uma porção e, desse modo, a diferença entre ambos é determinada pela extensão. Mais uma vez, a idéia de escala está precedendo a definição do lugar e do espaço. Em outras palavras, o zoom que aplicamos sobre o nosso objeto de pesquisa é o que nos dirá o que é o lugar, o espaço geográfico particular e quais atributos enxergamos.

Nesse contexto teórico, o autor (Brunet, 
1990 ; 2001) formulará a proposta metodológica dos coremas, talvez um dos esforços de formalização melhor sucedidos em geografia. Os coremas são as estruturas elementares do espaço, uma espécie de alfabeto para o espaço e para a geografia (Scheibling, 1994). Brunet pretende ter alcançado o elo que falta, na sua opinião, entre a teoria geográfica sobre o espaço em geral e os espaços particulares. Ele acredita que, graças aos coremas, será viável superar uma contradição clássica entre perspectivas nomotéticas e ideográficas. Sua busca, que certamente não é original, é a de encontrar uma ponte entre uma ciência do espaço e um conhecimento dos lugares. Tratase de encontrar estruturas significativas que possam ser aplicadas num jogo que vai de um método dedutivo a um método indutivo, propondo criar símbolos para as linhas, para as redes e para as áreas e aplicar isto em diferentes situações espaciais, por exemplo, áreas de contato entre dois países. Desse modo, ficariam evidentes as relações que se dão entre as extensões e as ações da sociedade: as leis do espaçamento, as leis da distância, as leis da gravitação, em relação às ações sociais de apropriação, de exploração, de comunicação. É uma sintaxe e uma semiologia do espaço geográfico que pretende uma aproximação entre a extensão vista como categoria constitutiva do espaço e a ação social, cujo esforço de transformação espacial é reconhecido, porém sem conceder-lhe o status de elemento constitutivo do espaço.

Mesmo que silenciosa, sua preocupação com a incapacidade de uma certa geografia regional para elaborar uma teoria do espaço geográfico parece discretamente revelada com sua proposta de uma teoria do espaço abstrata mas aplicável.

Ainda na França, outros autores têm desenvolvido uma perspectiva mais crítica do espaço em relação à extensão e à escala. Grataloup (1979), por exemplo, questiona o que ele chama de raciocínio inverso da lógica geográfica, isto é, partir da dimensão para chegar à qualificação. Partimos dos limites, para depois qualificar o espaço ou um lugar. Enquanto Jacques Lévy (1997, p. 349) alertanos: a escala é uma preocupação valiosa desde que compreendamos que "a medida da distância é um enjeu e não uma condição prévia da reflexão geográfica". No Brasil, discutindo questões de escala e regionalização, Rogério Haesbaert (2002, p. 104) propõe ultrapassar a definição de escala como mera "delimitação física, cartográfica, de um espaço passível de ser matematicamente medido" e entendê-la sobretudo como conteúdo.

Outra é a abordagem de Benno Werlen (2000). Segundo ele, é mister abandonar a geografia dos objetos e produzir uma geografia dos sujeitos. É como se asseverasse que essa geografia dos objetos nunca libertar-se-á da primazia da idéia de extensão. Portanto, a única solução possível parece ser desconsiderar toda essa pesada bagagem e propor uma geografia como ciência da ação. É preciso, segundo Werlen, olhar o espaço a partir da ação. O espaço, dirá ele, não existe materialmente, é um conceito classificatório, um quadro de referência para os conteúdos físicos das ações. Não se trata de negar o substrato físico, mas de vê-lo apenas como um quadro para a ação. A ação racional se dá sobre uma materialidade que é geométrica, porque é capaz de calcular os pontos sobre os quais se realizará. De alguma maneira, podemos coincidir com Benno Werlen no sentido de que a extensão tem sido um conceito-obstáculo que inviabilizou uma redefinição da nossa disciplina. Sua proposta é formular uma nova epistemologia geográfica a partir da ação.

Num certo sentido, essas epistemologias fundadas em torno da extensão privilegiaram, do ponto de vista do método, a razão e nunca a emoção (Santos, 1996a). O que podemos formular e reconhecer a partir de uma epistemologia da extensão são os espaços da racionalidade, isto é, os espaços que podem ser explicados pela idéia de distância e pelas suas diferentes formas de vencê-la. Ontem, o papel forte da razão na geografia, promessa de seu caminho para a cientificidade, fundou-se na 
herança do século das luzes, que ajudou a constituir uma disciplina em torno de idéias como região, gênero de vida, paisagem. Conceitos formulados na Europa e transplantados como um método de percepção à periferia, eles revelavam no seu âmago a idéia de extensão e da razão colonial. Era absolutamente racional a empresa colonialista e a geografia, nesse esforço de inventariar as descobertas, buscava contribuir ao debate com noções como limite, área, região, em definitivo, extensão.

Não podemos esquecer, mais tarde, as contribuições de uma certa geografia anglosaxã, que também foi tributária de uma epistemologia da extensão. Primeiro, os alemães e, depois, os americanos buscaram constituir uma geografia na qual a centralidade dos conceitos geométricos era evidente. Do alvorescer da corologia, que teve uma pretensão teórica na Alemanha, até as formulações e reformulações nos Estados Unidos, onde seu conteúdo ganhou uma visão pragmática, essa epistemologia foi novamente capaz de oferecer resultados. A idéia de extensão e também de área foram um suporte para a exploração tecnificada dos recursos naturais, no contexto de uma nova empresa colonizadora, ainda que o mundo preferisse agora os eufemismos. A famosa Aliança para o Progresso da América Latina teve um papel marcante na imposição de novos usos do território e, nesse momento, os saberes geográficos foram fundamentais. Havia sempre a insistência na distância, na área, na extensão e na produção de espaços racionais.

Nos dias de hoje, essas geografias geométricas e racionais continuam a ter um papel básico na edificação das forças econômicas e científicas que estão realizando a globalização, isto é, a formulação de espaços de pontos, de verticalidades, de redes, que coexistem, paradoxalmente, com um conceito de região como uma realidade pétrea. A conseqüência de tamanhas distorções é a subordinação da nossa disciplina a um papel menor. É a superioridade da razão e dos seus resultados, que se pretendem extensivos, ostensivos, visíveis. Tantas vezes, geografias ao serviço do mercado ou de um planejamento sesgado parecem ter no seu âmago a idéia de que o mundo só se explica pela razão e o produto da razão relaciona-se à distância. Assim, diminuindo as distâncias produziríamos a inclusão. Todavia, nosso período histórico está mostrando o fracasso dessa idéia. A diminuição técnica das distâncias (tempo, custos, percepção), que sob certas circunstâncias hoje assistimos, não assegura a inclusão. Os graus de inclusão buscados, imaginados ou declarados não se alcançam, provavelmente porque os nossos saberes continuam atrelados a essa epistemologia naïf. Nela, a emoção não participa nem deve participar do processo de conhecimento. A superioridade do conhecimento científico, em relação às demais formas de conhecimento, é certamente dada pela razão e pelos seus resultados. A emoção não é negada, mas ela não pode integrar o caminho da ciência. Imaginar que a emoção possa contribuir no entendimento do mundo significa, por exemplo, dar um papel maior à intuição no caminho do método científico. Ontologicamente, a emoção significa aglomerações permanentes e transitórias, isto é, gente junta ou uma certa imobilidade, e não apenas redes, economia pobre ainda que vista como "irracional" e não apenas modernidade, contigüidades na cooperação sem que isso seja obrigatoriamente sinônimo de grandes extensões ou de relações longínquas. Mas, estender o que é considerado racional constitui o caminho certo da ciência e da política e revela a superioridade da razão e dos seus resultados.

Uma epistemologia assim idealizada parte de separar processos e resultados. O problema é quando uma disciplina se propõe, como ponto de partida, aquilo que é um resultado e desiste de entender os processos, ficando satisfeita somente com a representação dos resultados. É por isso que, tantas vezes, a geografia não ganha um valor explicativo, permanece dando mais importância ao resultado e é uma geografia que não fala de outra coisa que não seja tamanho, forma, sítio, limites. Há uma espécie de recusa ao processo 
que é, afinal, a recusa à atualidade. Vemos as coisas, porém temos que ver como elas são presentificadas pela ação (Sartre, 1979; Santos, 1996a). E assim, quando nos contentamos com os resultados, recusamos a teorização, que é a atualização das formas materiais e imateriais do mundo. Quando se faz uma geografia de resultados, de formas, tamanhos e limites, dificilmente se pode teorizar. Nesse movimento, não são poucos os que começam a descobrir que a falta de teorização está reduzindo a geografia a uma ciência secundária. Para uns, que não conseguiram resolver os antigos traumas da disciplina, trata-se de matematizar ainda mais ou de criar uma simbologia como os coremas. Para outros, a renovação não passa pela transformação das categorias em conceitos, preenchendo-os da atualidade, mas de abandonar, junto das categorias, os elementos constitutivos do espaço que elas pretendiam mostrar.

\section{Epistemologia da existência. Por uma geografia existencial}

Uma certa insatisfação advém desse conjunto de idéias que estamos chamando epistemologia da extensão, ou seja a consideração do extenso, da distância, como base ontológica, a partir da qual partimos e somos capazes de criar uma matematização e uma simbologia para o espaço. Uma reflexão fundada na razão calculante que não resolveu os problemas do mundo nem os problemas seculares da geografia. O espaço geográfico é visto apenas como um cenário, onde a vida se desenvolve. Ocupa-se, assim, nossa disciplina mais do cenário e menos da vida.

Não buscamos aqui dar respostas, mas apenas levantar algumas questões para o debate. Nossa proposta é partir de uma outra premissa para a reflexão, a idéia de existência. Insistíamos que a existência, muito mais do que a distância, parece ser hoje o problema do homem. Mas se a existência é o problema do homem, então pode ser interessante tomar alguns ensinamentos dos filósofos existencialistas na busca de construir uma nova epistemologia geográfica. Com Heidegger (1958) apreendemos que o homem é o único ser na vida, entre todas as formas de vida, capaz de perguntar o que é a existência. Ele está no meio de outros existentes e tem a capacidade de se fazer essa indagação. E uma primeira resposta é que existir é estar no mundo, existir não é unicamente estar dentro de mim, mas estar fora de mim, estar no mundo, estar fora. A palavra "existência", que vem do latim existentia, significa exatamente estar fora, estar no mundo (Borzaga, 1966).

Mas, estar no mundo nos chama imediatamente para uma outra noção, que nos parece fundamental em geografia, que é a idéia de situação. É o próprio Heidegger quem diz que estar no mundo é estar em situação. Estamos no mundo em situações. A existência é um conjunto de situações. Estamos com as coisas, com os outros homens e numa esfera de significados. De alguma forma, estamos compartilhando valores morais, culturais, civilizatórios, que nos dão uma oportunidade de entendimento. É a cultura que nos oferece uma cosmo-visão, pois vemos o mundo a partir dela.

A existência é, na análise de Heidegger, uma situação concreta e consciente na qual está cada homem. Vivemos em situações concretas, hic et nunc, e não em situações idealizadas. Por isso, esse filósofo vai propor a palavra "dasein" que, de alguma forma, parece sintetizar a idéia de situação, de existência, de estar no mundo, de estar com os outros. Mas, ele insistirá que o dasein, essa situação do homem, transcende o próprio homem. Em cada situação concreta transcendemos em relação a nós próprios e aos outros existentes e às coisas ou, em outras palavras, somos capazes de imaginar e formular um projeto para o futuro. O dasein transcende o si próprio levando-o para outros existentes, transcende as coisas presentes levando para coisas futuras, transcende entidades particulares para vê-las organizadas no universo total. Estamos aqui numa situação concreta, mas há um universo acontecendo e poderíamos, nesse mesmo presente, estar aqui 
ou estar em outro lugar. Isto é o que faz com que o homem seja capaz de transcender e imaginar utopias, projetos, sonhos.

Estar no mundo não é apenas um problema de distância, de limites, de razão ou de resultados. A pergunta pela existência que parece bastante teórica ou abstrata não o é, porque diz respeito ao que há de mais básico na vida de cada um de nós e na vida de uma sociedade. $E$ isso nos conduz, de forma mais concreta, ao espaço. Talvez a extensão e a distância sejam um esforço de abstração maior.

Discutindo a existência e as situações, parece-nos esclarecedora a idéia de práticoinerte de Sartre (1979). O prático-inerte é o reflexo puramente objetivo do homem, isto é, a ação depositada nas coisas, algo que é mais ou menos externo ao homem, mas que lhe pertence. É a ação cristalizada nas formas materiais, nas formas jurídicas, nas formas culturais, nas formas morais. A atividade do homem retornada, como diz o próprio filósofo.

Não significa recriar um certo determinismo, mas reconhecer a inércia do que existe (Santos, 1996a). A ação é capaz de transformá-lo, mas toda ação parte, se localiza, se situa nesse prático-inerte. Portanto, a existência defronta-se com o prático-inerte, com aquela objetivação da ação, com aquela prática depositada nas coisas que faz parte da situação e, portanto, da nossa existência. Quando chegamos ao mundo, passamos a integrar um meio material, um contexto cultural, religioso, moral, econômico que podemos, até certo ponto, transformar. Não há existência que se defina sem considerar esse prático-inerte. Não há situação concreta que não seja construída sem a mediação dessa ação cristalizada.

Mais tarde, Jean-Paul Sartre (1990) define o prático-inerte como uma coisa no homem que não é o homem total e que, de certa forma, é um reflexo puramente objetivo do homem. É a atividade do homem que retorna. O homem total é aquilo que o homem fez, mais também o que ele está fazendo, o que ele sonha, o que ele projeta. Então o prático-inerte diz respeito somente àquilo que ele já fez. Assim, não há a transcendência do Heidegger sem o prático-inerte do Sartre. Não há projeto realista sobre o futuro político - falando em termos da vida social - que se possa fazer sem a geografia, sem a análise do espaço. Por um lado, não há situação concreta sem práticoinerte. Por outro lado, só é possível elaborar um projeto conhecendo as situações concretas. Em outras palavras, só é possível o projeto conhecendo a realidade, o particular, o lugar, mas sabendo ao mesmo tempo que o futuro, isto é, o universal, o não realizado, o mundo, é um conjunto de possibilidades. Portanto, o futuro não é obrigatoriamente a reprodução do presente, uma vez que reserva um conjunto de possibilidades (Santos, 1996a; Santos, 1996b) e reserva também aos atores um conjunto de escolhas; cada um escolhendo segundo o seu poder, segundo a sua situação concreta.

Os traços fundamentais de uma situação nunca são estáticos nem inexoráveis. A vida que se desenvolve numa situação nunca foi o produto de uma escolha única, de uma situação imutável, inexorável, sempre houve um conjunto de possibilidades. Todavia, segundo a situação da qual partimos, conforme nossa posição na sociedade, o grau de constrangimento não é o mesmo. Existem mais caminhos possíveis dos que, de fato, foram concretizados ou geografizados. Mesmo quando nos referimos ao que está aí, ao prático-inerte, sabemos que também foi produto de uma escolha entre possibilidades. Não é apenas imaginar que temos um mundo de essências que obrigatoriamente se transformará num mundo de existências.

Mas aqui também ganha um lugar importante a idéia de evento. Para Milton Santos (1996b), o mundo é uma latência, um conjunto de essências, um universo de meios ainda nãorealizados, um conjunto de possibilidades. Os eventos transformam as essências em qualidades e quantidades, produzem a extensão. 
Partimos dos existentes concretos para construir nossas interpretações. Quais eram as possibilidades técnicas e políticas no século XV? Nem todas foram historicizadas. Quais as invenções relativas à navegação? Quais os conhecimentos de hidrografia? São coisas que realmente existiram e que se combinaram de forma diferente nos lugares. Nunca estamos partindo de um mundo de seres ideais. É uma análise existencial porque parte do espaço. Como diz Milton Santos (1996b), o espaço é o existir, a sociedade é o ser. A sociedade só se realiza no espaço. O mundo só existe nos lugares, pois a história se constrói nos lugares. Entre essas possibilidades e esses existentes concretos temos os eventos. São os eventos que transformam as possibilidades em existentes, mas os eventos não são alheios nem indiferentes ao que existe. Não há evento sem objeto, não há evento sem ator. Quando uma corporação global escolhe uma cidade para instalar uma fábrica, está produzindo um evento a partir de um conjunto de possibilidades e escolhendo o que ali existe. Por isso, o evento é o veículo da história, produz a existência. E o evento surge do casamento entre o que é possível e o que existe. Não partimos do mundo das idéias de Platão, trata-se de uma dialética entre, de um lado, o que existe, o prático-inerte, a configuração territorial e, por outro, as possibilidades do período. Essa é a razão pela qual nem todos os dados do período existem em todos os lugares, nem produzem as mesmas extensões. Nem todas as técnicas, nem todas as informações, nem todas as manifestações da finança chegam a todos os lugares. Os eventos transformam as essências e possibilidades em qualidades e quantidades num lugar determinado. São os eventos que operam a metamorfose entre possibilidade e existência. E, assim, a existência ganha uma certa extensão. É a história que produz extensões diferenciadas, portanto não é aconselhável que uma geografia que se pretende uma disciplina histórica e crítica, parta sempre da extensão, que considere como dado aquilo que é um produto histórico.
Por isso, não podemos deixar de lado a idéia de período, que é um conjunto de possibilidades num sistema de tempo. No mundo do século XVI havia um dado conjunto de essências, de possibilidades, de latências, que eram historicamente realizáveis. Era possível fazer isto ou aquilo. As possibilidades do século XVI permitiram a certas potências européias, que saíam do feudalismo e entravam na fase do grande comércio, produzir uma extensão alcançando as terras americanas. Uma extensão nova fora produzida.

No mundo do século XXI, as possibilidades são outras. Portanto, quando falamos de possibilidades também referimo-nos às possibilidades de produzir extensão. Hoje, estamos vivendo a possibilidade concreta de produzir uma extensão também revolucionária, graças às comunicações e transportes modernos e, particularmente, ao discurso atual que é capaz de produzir a ampliação e reprodução de uma cosmovisão e de um modo de vida. A partir de um dado sistema técnico, um discurso tornou-se planetário, o chamado pensamento único. De modo tal que a extensão da qual nosso mundo é capaz questiona todo tipo de limites.

As variáveis que comandam o período atual são capazes de produzir uma extensão tal que puseram em xeque a nossa disciplina, anunciando que a região não existe mais, que o espaço não existe mais e toda uma profusão de outras metáforas. Portanto, um saber, cuja função tradicional era a de fatiar o espaço em pedaços e mostrar suas diferenças, não tem mais razão de ser, porque o mundo tornou-se homogêneo. Mas nesse conjunto de possibilidades que define nossa época, e como em todas as demais, nem todas as possibilidades se tornaram existências, nem todas ganharam a mesma extensão. Mas, quais são as variáveis, quais são as existências cuja extensão tornou o planeta único? A finança, a informação, a tecnociência pretendem completar essa unificação, mas não estão presentes em todas as formas de trabalho. Isto significa que os eventos não são todos iguais. Há eventos 
que são capazes de produzir solidariedade orgânica e outros, os mais visíveis, são capazes de produzir solidariedade organizacional (Santos, 1996a). Ao olharmos para uma região, poderemos descobrir, talvez mais visivelmente, os eventos que encarnam uma solidariedade organizacional, como por exemplo a implantação de um grande banco que muda a equação da circulação do dinheiro regional. Mas haveria também que olhar, nessa região, um conjunto de outros eventos, cujo berço é aquele pedaço do território como, por exemplo, uma associação de produtores regionais. Trata-se de um evento capaz de produzir uma solidariedade orgânica, e isso existe concomitantemente com os produtores de solidariedade organizacional. O problema é que, quase sempre, nossas lentes são preparadas para ver o que é organizacional.

O período contemporâneo produziu uma extensão que cria uma sinonímia entre planeta e ecúmeno. Portanto a extensão assim entendida não é apenas um cenário onde a vida se desenvolve, ela é um prático-inerte, é o mundo que cada geração recebe da geração anterior. As possibilidades da globalização iniciaram a transformação de um prático-inerte, de uma extensão herdada, que tinha sido produzida pelo mundo um século antes. Iríamos ainda mais longe, a extensão que temos hoje, o prático-inerte que define o mundo resultou de uma escolha possível. Havia outras possibilidades. A extensão que é a nossa contemporânea não era inelutavelmente a extensão das grandes rodovias, unindo os lugares mais competitivos aos portos. Tornar 0 mundo um espaço reticular era uma opção possível, ao tempo que capilarizar as áreas mais esquecidas poderia ter sido outra forma de produzir a extensão.

Esse é o processo de empiricização do tempo. O tempo se empiriciza em extensão, mas também em ações, em novos sistemas organizacionais, em normas jurídicas, em formas culturais. O espaço é esse conjunto complexo de existências materiais e imateriais. A isso denominamos território usado (Santos, 1994; Santos e Silveira, 2001) e estamos chamados a compreender seu funcionamento e não apenas suas formas e tamanhos.

Em outras palavras, quando as possibilidades se encontram com o que já existe, com esse prático-inerte, com essa extensão, tornam-se novas existências, mudam as formas-conteúdo, criam especializações. Só que este mundo que nós temos diante de nós para ser investigado, não é apenas um mundo de especializações produtivas modernas, mas sobretudo um espaço banal. Trata-se do espaço onde as ações e os objetos modernos e perfeitos coexistem com os objetos imperfeitos, envelhecidos, "atrasados".

Por que se cria um espaço banal que é o espaço de todos e não apenas o espaço de pontos, de verticalidades, da razão tecnocientífica? Porque os eventos produtores da existência não são todos da mesma natureza. Nem todos os eventos são produtores de racionalidade, nem todos os eventos são produtores de espaços de pontos. Podemos entender os eventos como produtores de um acontecer homólogo, um acontecer complementar e um acontecer hierárquico (Santos, 1996a).

Os conteúdos e processos devem ser investigados. A idéia é captar a vida que está nas formas, e não apenas as formas. E a ênfase nos processos exige a teorização, isto é, encontrar as categorias, os conceitos que sejam mais apropriados à história do presente, às formas e processos do presente. Quiçá, assim, cheguemos a elaborar uma verdadeira geografia da existência.

A extensão não é uma coisa dada, é historicamente produzida; há um processo histórico e lógico que dá como resultado a extensão. Mas poderíamos dar conta da extensão de formas diferentes, por exemplo, pensando nas variáveis determinantes do período. Podemos, a partir daqui, preocupar-nos sobretudo com o espaço de redes. Em outros termos olhamos para a extensão historicamente produzida e tentamos descobrir essa lógica e essa história da produção a partir das variáveis 
determinantes. Retratamos o sistema bancário ou um certo número de corporações globais. É um esforço necessário e possível, quando não esquecemos que é apenas uma parte do espaço, um espaço de pontos. Estamos mostrando um espaço feito de eventos hierárquicos, verticais, produtores de uma solidariedade organizacional. Uma holding instala-se ali onde o território tiver a renda per capita mais alta, onde houver uma densidade demográfica interessante, uma dotação viária e de telecomunicações importante, uma densidade normativa (Silveira, 1997) apropriada porque essa é sua política. O resto do território é feito de "áreas desinteressantes". Mas sua escolha interesseira partiu de considerar todo o espaço.

Por essa razão, nossa geografia, se pretende continuar sendo crítica, não pode desconsiderar aspectos do espaço nem continuar a analisá-lo como se fosse estático.
O espaço banal é o lugar do acontecer solidário (Santos, 1996a; 1996b), independentemente da força que os atores tenham para criar extensões. É o espaço da emoção porque nem todas as ações nem todos os objetos aderem à racionalidade do período. A realidade não é dada apenas pela economia, ou apenas pela política, ou apenas pela cultura. Essas são reduções da realidade que privilegiam um aspecto em detrimento do todo, é um falso aprofundamento que acaba por esquartejar a realidade. Uma epistemologia dos processos busca captar a vida nas formas, as formas da existência, mesmo que elas não tenham força suficiente para criar o extenso. É a totalidade da existência o que interessa a essa geografia. $\mathrm{E}$, para isso, o mundo não pode ser cindido a partir de enfoques inquestionáveis, como os setores da economia, as redes, as regiões pétreas, mas a partir do nosso concreto pensado: a existência em situação no seu respectivo período histórico.

\section{Bibliografia}

BAILLY, Antoine S. (coord.). (1984). Les concepts de la géographie humaine. 2ed. Paris: Masson, 1991, pp. 43-53.

BORZAGA, Reynold. Contemporary Philosophy. Phenomenological and Existential Currents. The Bruce Publishing Company: Milwaukee, 1966. BRUNET, Roger. Le déchiffrement du monde. In: BRUNET, Roger e Olivier DOLLFUS. Mondes nouveaux. Livre I. Volume I de Géographie Universelle. Paris: Hachette-Reclus, 1990.

BRUNET, Roger. Le déchiffrement du monde. Théorie et pratique de la géographie. Paris: Belin, 2001.

GRATALOUP, Christian. "Des échelles". Espaces Temps, Paris, n.10-11 (Région Enquête sur un concept au-dessus de tout soupçon), pp. 7279, 1979.

HAESBAERT, Rogério. Territórios Alternativos. Niterói: EdUFF, São Paulo: Contexto, 2002.

HEIDEGGER, Martin. Essais et Conferences. Paris: Gallimard, 1958.

PINCHEMEL, Philippe; PINCHEMEL, Geneviève.
(1988) La Face de la Terre. Éléments de Géographie. 3 ed., Paris: Armand Colin, 1994. SANTOS, Milton. "O retorno do território". In: SANTOS, Milton, Maria Adélia A. de SOUZA e María Laura SILVEIRA. Território: Globalização e Fragmentação. São Paulo: Anpur-Hucitec, 1994, pp. 15-20.

SANTOS, Milton. A natureza do espaço. Técnica e tempo, razão e emoção. São Paulo: Hucitec, $1996 a$.

SANTOS, Milton. El espacio banal, una epistemología de la existencia. In: Universitat de Barcelona, Solemne Investidura de Doctor Honoris Causa, novembro 1996b.

SANTOS, Milton e María Laura SILVEIRA. O Brasil. Território e Sociedade no início do século XXI. Rio de Janeiro: Record, 2001.

SARTRE, Jean-Paul (1960): Crítica de la Razón Dialéctica. Precedida de Cuestiones de Método (Critique de la Raison Dialectique - précédé de Questions de Méthode, Gallimard, 1960). Traducción de Manuel LAMANA. 3 ed., Buenos 
Aires: Losada, 1979.

SARTRE, Jean-Paul. Situations Philosophiques. Paris: Gallimard, 1990.

SCHEIBLING, Jacques. Qu'est-ce que la géographie? Paris: Hachette, 1994.

SILVEIRA, María Laura. Concretude territorial, regulação e densidade normativa". In: Experimental, ano I, n. 2, Laboratório de Geografia Política e Planejamento Territorial e Ambiental, Departamento de Geografia, Universidade de São Paulo, março 1997, pp. 3545.

SILVEIRA, María Laura. "Imperio de la escala, escala del imperio". In: Revista Universitaria de Geografía, vol.8, no 1 e 2, Bahía Blanca, 1999a, pp.105-113.

SILVEIRA, María Laura. "Escala geográfica: da ação ao império?". In: Terra Livre, ano 20, v. 2, n. 23, pp. 87-96.

SILVEIRA, María Laura. "Uma situação geográfica: do método à metodologia", in Território, Laboratório de Gestão do Território LAGET, Universidade Federal do Rio de Janeiro, ano IV, no 6, janeiro-junho 1999b, pp. 21-28.

WERLEN, Benno (1988): Society, Action and Space. London, New York: Routledge, 1993. 